is not barred by lens imperfections, but by the polarization layers which form especially in the objective aperture ${ }^{6}$. This is one more reason for taking up their study in earnest.

Years ago, when highly corrected lenses appeared more important than at the present time, I of ten thought that it would be desirable to know the fields corresponding to ideally stigmatic lenses, regardless of the difticulty of their realization by current laboratory methods. After labouring on the problem without success for some time, I dismissed it from my mind, but recently when I again gave attention to the subject I found a very simple way leading to the solution. Though the result itself may not be of practical importance at the present stage of electron optics, I think that the method by which it is derived may be of interest.

Hamilton's Principle can be expressed in a form identical with Fermat's Principle

$$
\int n \cdot d s=\text { minimum, }
$$

where $d s$ is an element of the trajectory and $n$ is the electron optical refractive index. Let us apply this to the trajectories in the meridian plane of a lens. In this case $n$ is independent of the direction, not only in electrostatic lenses, but also in the magnetic type, if we allow for the rotation of the trajectory around the axis.

Let us now map the meridian plane of the lens on a suitably chosen surface by a transformation

$$
n . d s=d S,
$$

where $d S$ is the line element on the surface corresponding to $d s$. As $n$ is isotropic, the transformation is isomorphic. A surface on which the meridian plane of the lens can be mapped in this way may be called a geodetic surface, as every electron trajectory will be mapped on it as a geodetic line?

This leads straight to the 'ideal lens', as it is obvious that the geodetic surface of an ideal lens must be a sphere. On a sphere the geodetics are great circles, and the great circles running through any point intersect again in its antipole, which can be considered as the rigorous image of the point considered. We can now map the sphere on a plane by any isomorphic projection known in cartography, and obtain an ideal two-dimensional lens. In order to obtain the ideal three-dimensional lens we choose the stereographic projection, on account of its central symmetry. This gives the following law for the distribution of the refractive index as a function of the radius vector $r$ in the meridian plane :

$$
n / n_{0}=\left(1+r^{2} / r_{0}^{2}\right)^{-1},
$$

where $n_{0}$ is the refractive index at the centre, and $r_{0}$ a length which characterizes the dimensions of the lens. If we imagine this distribution rotated round any axis, we obtain the ideal three-dimensional lens. Because of its spherical symmetry, any trajectory will be contained in a meridian plane. The trajectories are one and all ellipses. An image of any point at a distance $r_{1}$ from the centre will be formed rigorously at a point on the same diameter at a distance $r_{2}$, and the simple relation between the two is

$$
r_{1}, r_{2}=r_{0}{ }^{2} \text {. }
$$

Image formation is therefore the geometrical transformation known as inversion. It can be proved that the three-dimensional ideal lens is unique. If there were other ideal lenses, they could be derived from the one described by isomorphic transformations. But according to a theorem of Liouville the group of isomorphic transformations in three dimensions is identical with the group of inversions, and according to a theorem of Cayley and Klein the group of inversions represents, by stereographic transformations, the rotations of a sphere on itself. As rotations of the geodetic sphere on itself are irrelevant, the ideal lens is transformed into itself, and is therefore unique.

Though it may be satisfactory to know that the ideal lens exists in the mathematical sense of 'existence', no immediate practical application can be expected, as it cannot be realized without space charges. The same is true of the infinite number of two-dimensional (cylindrical) ideal lenses, though some of these may be capable of approximate realization. These are all derivable from the 'stereographic' distribution by any conformal representation in which the action is kept invariant:

$$
n \cdot d s=n^{\prime} \cdot d s^{\prime}
$$

It may be hoped that such representations will have other, less ambitious but more immediately fruitful applications, as they allow the transformation of one electron optical problem into another, and may even hold the key to certain space-charge problems, for which no satisfactory mathematical treatment has yet been found.

${ }^{1}$ Scherzer, 0., Z. Phys., 101, 593 (1936),

'Rebsch, R., Ann. Phys., 5, 31, 551 (1938).

' Hottenroth, C., Z. Phys., 103, 460 1936). Recknagel, A., Z. tech. Phys., 17, 643 (1936).

'Hillier, J., and Vance, A. W., J. Inst. Rad. Eng., 167 (April 1941).

'Zworykin, V. K., Hillier, J., and Vance, A. W., J. App. Phys., 12, 738 (1941).

${ }^{6}$ Hillier and Vance, J. App. Phys., 12, 171 (1941).

'Schröuing r, E., Ann. Phys., 4, "79, 489 (1926). Whittaker, "Analytical Dynamics", 4 th ed., p. 254.

\section{HEALTH EDUCATION IN GREAT BRITAIN}

$M$ ANY of the most important institutions in Great Britain have, like Topsy, 'just growed', and among them is the Central Council for Health Education. Set up originally in 1927 as an offshoot of the Society of Medical Officers of Health, it has grown until it is now recognized by the Government as "the one agency for general health education in England and Wales", with thirty-nine members of staff and fifty-four active recognized lecturers. Since the Council, at the instigation of the Ministry of Health, took over in April of this year the major part of the work previously carried out by the British Social Hygiene Council, together with most of the staff responsible for it, its activitios have increased enormously. The Council has regional oftices in various parts of the country, which facilitates work considerably, and encourages local initiative.

The general public is probably most familiar with the Council's poster advertisement-indeed "Coughs and Sneezes spread Diseases" has become a national slogan. Posters are available for the use of local authorities in sufficient diversity to cover most conceivable needs. The disease-spreading proclivities of the rat and the fly ; the life-histories of the bug, the louse and the scabies mite; the importance of diphtheria immunization and whooping-eough inoculation; the desirability of rambling, cycling and camping; the benefits to be derived from breastfeeding and attendance at infant welfare elinies-- 
all these and many other health lessons may now be brought to the attention of the public by display on the hoardings. Local authorities are not slow to appreciate the advantage of this centralized poster production, as evidenced by the fact that in the first six months of this financial year, the Contral Council has disposed of some twenty-three thousand posters and bills.

Apart from posters, the main medium of printed propaganda is the leaflet. Most of the Central Council's leaflets fall into several attractive series such as "Health Hints", "Hints from the Health Department" and "Shelter Bulletins". These cover a wide field of health education, ranging from brief outlines of diseases such as diphtheria, measles, whooping cough, infantile paralysis, tuberculosis and influenza, to the importance of bodily and sartorial cleanliness, sleep and the adequate feeding of baby, toddler and expectant mother. In addition, several pamphlets are available; while those leaflets and pamphlets dealing with the biological approach to sex education and the problems of venereal diseases (taken over from the British Social Hygiene Council) are, after suitable revision, being re-published in similar format. The scope of this type of publicity may be estimated by the fact that in six months some 885,000 leaflets and pamphlets have been distributed by the Central Council. Not content with this range, the Council is actively engaged on the preparation of new pamphlets dealing with the health of schoolchildren (from the points of view both of the teacher and of the parent), with the problems of adolescence (for youth leaders), with the health of factory workers, and with biology as a medium of health education in the school ; and of new leaflets concerning the health of the worker, the care of the feet, advice to dyspeptics, and other topics. In addition, an illustrated health booklet for children will soon be available.

A central health education agency could scarcely regard its work as satisfactory in the absence of a periodical, and the Central Council is in the fortunate position of having two. Better Health, a small popular monthly, achieves a circulation of 50-60,000, and, when paper limitations are removed after the War, should reach many times this figure. In addition to a popular magazine for the general public there has, however, been for many years a real need for a journal of a more specialist nature, to cater for those many people actively working in the field of health educa. tion. This need should be met by the publication, in January of 1943, of the first number of a new quarterly, Health Education. Articles by specialists will help to give educationists more information on medical matters, and medical people more on matters of education.

The first number will contain a message from the Minister of Health. Dr. Allen Daley (chief medical officer of the London County Council) will contribute an article describing the beginnings of health education in Great Britain, while Prof. J. M. Mackintosh will give his views of the primary aims in health education, and Dr. Charles Hill (chairman of the Central Council) will consider radio as a medium of health education. Mr. W. B. Little will discuss health education from the point of view of the school-teacher, and Dr. J. L. Picton from that of the general practitioner, while the problems of sex education will be considered by Mr. Cyril Bibby (education officer of the Central Council). This new journal should prove of the greatest value to medical practitioners, teachers, youth leaders, social workers, medical and educational administrators and indeed to all seriously interested in the matter of health education.

No educational body to-day can afford to neglect the medium of the film, and the Central Council has not been backward in this respect. It now has available for the use of local authorities some fifty films, covering the most varied aspects of health education. Droplet infection, nutrition, the care of the skin and of the feet, the conquering of fear, the historical development of the public health services, the biological approach to the study of sex and reproduction, the venereal diseases - all these are dealt with in the Council's films, in manners suitable for the most diverse audiences, from school-children and the general public to educationists and medical practitioners. Not content with this range of subjects the Council has at present in production new films on the head louse, venereal diseases, infant welfare clinics, and a film fantasy for children, showing the importance of cleanliness, exercise, fresh air, and good food.

During the last six months the Council's films have been shown at some four hundred special meetings. In addition, more than three hundred health films have been dispatched to a hundred borrowers. To meet this demand for visual health education the Central Council employs seven film operators, and possesses ten film and six film-strip projectors.

The radio is also a medium of the utmost importance, and it has not been neglected. In collabora. tion with the Central Council for School Broadcasting, the chairman of the Central Council for Health Education has given many health talks to school-children; and millions must hear him as the "Radio Doctor" in the B.B.C. programmes.

Important as all these methods of health education undoubtedly are, perhaps most potent of all is the spoken word of a lecturer to his audience. With the helpful co-operation of local authorities and the various national voluntary organizations, the Contral Council arranges large numbers of meetings for many different types of audience, and more often than not the meetings are illustrated by films. During the six months from April 1 of this year more than 75,000 people have been reached in this way.

This number is but a small part of the total population of Great Britain, but many audiences are highly selected, consisting of influential persons, who will pass on the knowledge obtained to, or will be influenced in their dealings with, many others. This is particularly true of the meetings for school-teachers, who have such a great influence over children and young people. Thus it is reasonable to expect that the 762 teachers who have during these six months attended lectures at eleven different centres in the country will, as the years go by, affect favourably tens of thousands of the future citizens of the country. These teachers' refresher courses have dealt with the biological approach to problems of sex and of health generally, and have been fairly thorough courses of up to twelve sessions. The Central Council has built up a comprehensive display library of biology and hygiene books, and teachers have been very grateful for the opportunity of examining it at the meetings.

Similar significance beyond the mere figures of attendance applies to the 1,566 youth leaders and welfare supervisors who have in the same period attended courses dealing with the problems of adolescence; and to the 1,111 parents who have taken part in meetings dealing with the sex and health education of children. 
An important feature of the work of the Central Council is the talks on sex and general health problems given directly to school-children and young people. No fewer than 1,466 of the former and 4,596 of the latter have attended courses of lectures given in this half-year in sixty different parts of the country, and all the signs are that the figures for the next half-year will be even greater.

During the period under consideration, approximately three thousand civil defence workers and seven thousand troops have attended meetings organized by the Central Council for Health Education, while factory meetings have reached some thirty-nine thousand workers.

Work of this variety and of this extent is possible only by the collaboration of skilled personnel and influential national organizations. Under its president the Archbishop of Canterbury, the Cantral Council meets as a widely representative body. Of Government departments, the Ministry of Health, the Board of Education, the Ministries of Food, Labour and Information, the Welsh Board of Health and the Scottish Education Department all have either representatives or observers on the Council or its Committees. In addition, there are representatives from the County Councils Association, the London County Council, the Association of Municipal Corporations, the Non-County Boroughs Association, the Metropolitan Boroughs Standing Joint Committee, and the Urban and Rural District Councils Associations.

The collaboration of the professions most concerned with health education is assured by representation from the Society of Medical Ofticers of Health, the British Medical Association, the Royal College of Nursing, the Dental Board of the United Kingdom, the British Dental Association, the Association of Directors and Secretaries for Education, the Association of Education Committees, and the National Union of Teachers. The field of health insurance is covered by representatives of the National Association of Insurance Committees, the Association of Welsh Insurance Committees and the London Insurance Committee, while collaboration with other health organizations is achieved by representation from the Conference of Aftiliated Sucieties. In addition, the Council's Educational Advisory Committee has the benefit of the knowledge and experience of representatives from the British Medical Association, the Association of Women Scionce Teachers and the Science Masters' Association, and of many distinguished educationists (see also NATURE of November 7, p. 529).

Thus for the first time Great Britain has a really large and representative organization with skilled personnel devoted entirely to the enormously important work of health education; and the country should benefit greatly from it.

\section{NEWTON TERCENTENARY ROYAL SOCIETY CELEBRATIONS}

$\mathrm{T}$ HE anniversary meeting of the Royal Society, which is held on Saint Andrew's Day, November 30 , was this year devoted, for the most part, to commemorating the tercentenary of the birth of Isaac Newton. The proceedings, which took place in the lecture theatre of the Royal Institution, were opened by Sir Henry Dale, president of the Royal Society, and the main part of his address is printed below.

We are within a few weeks of the three hundredth anniversary of the birth of Isaac Newton. Wherever the progress of our Western science and philosophy has become effective, men will remember what that event was to mean for the world. Newton, at the age of forty-three, when he had determined to abandon all further concern with natural philosophy, was induced at length, by Halley's friendly insistence, to give written form and system to the mathematical discoveries with which his amazing mind had been occupied over a period of some twenty years. The result was one of the greatest intellectual achievements in the history of mankind-the "Principia", providing for more than two centuries a framework for the mechanical interpretation of the universe and a basis for the building of physical science, and therewith of the material structure of our modern civiliza. tion.

We in Britain regard Isaac Newton as still, beyond challenge, the greatest of our men of science. Nor should the claim be limited to this island or to the British Commonwealth of Nations; for it was not until nearly half a century after Newton's death that former British colonists in North America began their development of an independent nation; and Newton is theirs as well as ours.
But, while we may proudly claim him as the countryman of all who share the birthright of the English tongue, the discoveries of science have belonged, and must belong again, to the whole world, and Newton's achievement is a part of the common heritage of all peoples. It cannot be doubted that, if it had fallen in normal times, this tercentenary would have been marked by the greatest of international gatherings, in which men of science and philosophers from all the world would have assembled to do honour to Newton's memory. It would have been natural then to expect leadership, in such an enterprise, from the only two institutions which were intimately concerned with Newton's career as a man of science-Trinity College, in Cambridge, and this our Royal Society of London. Our two foundations did, indeed, confer as to the wisdom of attempting by joint action, even in this year of war, to arrange such a restricted and domestic celebration as the present conditions would allow. We agreed, however, to put aside such planning for the present, carrying it forward in our hopes to the time when a world at peace may be able to join in international commemoration of an event which has meant so much for all mankind. May the time be not too far distant.

In the hamlet of Woolsthorpe, near Colsterworth on the Great North Road, some six miles south of Grantham, there is still a modest manor farm-house, with a small orchard in front of it. Here the Newtons lived, simple yeoman farmers, and here, two months after his father had died, Isaac Newton was born, a puny, premature infant, on Christmas day 1642, twenty years before the Royal Society was incorporated by the grant of its first Charter. The house stands but little altered since that day. The room in which Newton was born has a simple marble 